\title{
Efficacy and safety of vascular endothelial growth factor receptor tyrosine kinase inhibitors in the treatment of advanced thyroid cancer: a meta- analysis of randomized controlled trials
}

\author{
This article was published in the following Dove Press journal: \\ OncoTargets and Therapy \\ 7 March 2016 \\ Number of times this article has been viewed
}

\section{Wufuer Yimaer* \\ Aizizi Abudouyimu* \\ Ye Tian \\ Sailike Magaoweiya \\ Duman Bagedati \\ Hao Wen}

Department of Vascular Thyroid Surgery, Gastrointestinal Vascular Center, The First Affiliated Hospital of Xinjiang Medical University, Urumqi, Xinjiang Province, People's Republic of China

*These authors contributed equally to this work
Correspondence: Hao Wen

Gastrointestinal Vascular Center, The First Affiliated Hospital of Xinjiang Medical University, No I37, South Liyushan road, Urumqi, Xinjiang province 830054, People's Republic of China Tel +86 99| 4362974

$\mathrm{Fax}+869914364780$

Email haowen2015I2I2@sina.com
Background: We performed a systematic review and meta-analysis to determine the efficacy and safety of the US Food and Drug Administration approved vascular endothelial growth factor receptor tyrosine kinase inhibitors (VEGFR-TKIs) in the treatment of advanced thyroid cancer.

Patients and methods: We included prospective randomized controlled trials that compared VEGFR-TKIs with placebo for advanced thyroid cancer. The endpoints included safety (fatal adverse events [FAEs], treatment discontinuation, and any severe [grade 3 or 4] adverse events [AEs]) and efficacy (objective response rate, progression-free survival, and overall survival). The pooled relative risk (RR) or hazard ratio (HR) was calculated by using either random-effects or fixed-effects models according to the heterogeneity of included studies.

Results: A total of 1,614 advanced thyroid cancer patients from five randomized controlled trials were identified for analysis. Compared with placebo alone, VEGFR-TKIs significantly increased the risk of treatment discontinuation (RR: 3.80, 95\% confidence interval [CI]: 2.56-5.65, $P<0.001$ ) and any severe AEs (RR: 2.63, 95\% CI: $1.72-4.03, P<0.001$ ), but not of FAEs (RR: $1.24,95 \%$ CI: $0.65-2.39, P=0.52$ ). The use of VEGFR-TKIs in advanced thyroid cancer was associated with a significant improvement in objective response rate (RR: $8.73,95 \%$ CI: $1.72-44.4, P=0.009$ ) and progression-free survival (HR: $0.41,95 \% \mathrm{CI}: 0.27-0.61, P<0.001$ ), with a tendency to improve overall survival (HR: $0.83,95 \% \mathrm{CI}$ : $0.68-1.01, P=0.06$ ).

Conclusion: The use of small-molecule VEGFR-TKIs in advanced thyroid cancer did significantly increase the risk of treatment discontinuation and any severe AEs, but not of FAEs, compared with placebo alone. It is important for physicians to weigh the risk of toxicities as well as the potential survival benefits associated with VEGFR-TKI treatment in advanced thyroid cancer patients.

Keywords: angiogenesis inhibitors, toxicity, clinical trials, thyroid cancer, meta-analysis

\section{Introduction}

Thyroid cancer is the most common neoplasm of the endocrine system with incidence rates steadily increasing over the past 10 years. ${ }^{1}$ In $2014, \sim 62,980$ new cases of thyroid cancer were diagnosed and $\sim 1,890$ cancer deaths occurred from the disease in USA. ${ }^{2}$ Although the prognosis is excellent for the majority of patients treated by surgery, thyroid-stimulating hormone-suppressive therapy, and radioiodine ablation, with an overall survival rate of $97.7 \%$ at 5 years, ${ }^{3}$ local recurrence occurs in up to $20 \%$ of patients and distant metastases in $\sim 10 \%$ at 10 years. ${ }^{4}$ Until now, the medical approach 
for the treatment of advanced or metastatic thyroid cancer refractory to conventional treatment is considered particularly challenging and few therapeutic options are available for these patients. Historically, the role of cytotoxic chemotherapy has been quite limited in these patients due to low efficacy and unfavorable toxicity profile when used. ${ }^{5}$

In the past decades, a better understanding of the molecular events involved in the tumorigenesis of thyroid cancers has led to development of new targeted agents for the management of advanced and refractory disease. Previous research has shown that vascular endothelial growth factor (VEGF) is overexpressed and its main receptor VEGFR-2 is upregulated in many thyroid cancers, which is associated with neoplastic progression and aggressiveness. ${ }^{6}$ The VEGF and its receptors are, therefore, regarded as attractive therapeutic targets in the treatment of thyroid cancers. ${ }^{7}$ Since 2011, four tyrosine kinase inhibitors (TKIs) targeting vascular endothelial growth factor receptor (VEGFR) have been approved by the US Food and Drug Administration for thyroid cancer: cabozantinib and vandetanib for medullary thyroid cancer and sorafenib and lenvatinib for differentiated thyroid cancer. All of the four drugs are multikinase inhibitors that act on multiple molecular pathways involved in growth, angiogenesis, and local and distant spread of thyroid cancer. ${ }^{8}$ Sorafenib is a multitargeted TKI with inhibitory activity against VEGFR-2 and -3, c-Kit, platelet-derived growth factor receptor (PDGFR), rearranged during transfection (RET)/papillary thyroid carcinoma, and Raf kinases, and the Raf/Mek/Erk pathway (MAPK pathway). ${ }^{9}$ Vandetanib has a low molecular weight and a good inhibitory activity against VEGFR-2, and targets VEGFR-3, EGFR, and RET kinases. ${ }^{10}$ Sunitinib (SU011248) is a selective inhibitor of VEGFR-1, -2, and -3, PDGFR, c-Kit, and RET/papillary thyroid carcinoma subtypes 1 and $3 .{ }^{11}$ Lenvatinib is an oral, multitargeted TKI of VEGFR-1, -2, and -3, fibroblast growth factor receptor-1, $-2,-3$, and -4 , PDGFR- $\alpha$, RET, and KIT. ${ }^{12}$ To our best knowledge, there is no meta-analysis to assess the overall efficacy and toxicities of these four approved VEGFR-TKIs in advanced thyroid cancer. We, therefore, conducted this comprehensive meta-analysis to assess the efficacy and toxicities of approved VEGFR-TKIs in advanced thyroid cancer.

\section{Methods}

\section{Data sources}

\section{Selection of studies}

The Cochrane Central Register of Controlled Trials, PubMed (up to October 2015), and Web of Science (up to October 2015) databases were searched for articles. The search was extended to abstracts from oncology meetings containing the same terms ("VEGFR-TKIs", "vandetanib", "sorafenib", "lenvatinib", "cabozantinib", "advanced thyroid cancer", "metastatic thyroid cancer", "randomized controlled trial", and "humans"). Using the same search terms, we also searched abstracts and virtual meeting presentations from the American Society of Clinical Oncology conferences held up to October 2015 in order to identify relevant trials. An independent search of the Web of Science, Embase, and Cochrane electronic databases was also performed to ensure that no additional clinical trials were overlooked.

\section{Data extraction and clinical end points}

Data extraction and analysis were conducted independently by two independent investigators and any discrepancy was resolved by consensus according to the Quality of Reporting of Meta-Analyses guidelines. ${ }^{13}$

Clinical trials that met the following criteria were included: 1) Phase II and III trials in patients with advanced thyroid cancer; 2) random assignment of participants to treatment with VEGFR-TKIs or placebo alone; and 3) reporting data for at least one of the safety or efficacy outcomes. Independent reviewers screened reports that included the key terms by their titles and abstracts for relevance. Then, full texts of the relevant articles were retrieved to assess eligibility.

For each study, the following information was extracted: year of publication; first author; number of enrolled subjects; number of patients in each arm; median age; doses of VEGFR-TKIs administered; combination drug; median progression-free survival (PFS) (time to progression if not available), median overall survival (OS), objective response rate (ORR), fatal adverse events (FAEs), hazard ratios (HRs) for PFS and OS, treatment discontinuation related to adverse events (AEs), and any severe AE. The quality of included trials was rated using the five-point Jadad scale, which was based on the reporting of randomization method, blinding method, and withdrawals and dropouts. ${ }^{14}$

\section{Statistical analysis}

Incidence, relative risk (RR), and corresponding 95\% confidence intervals (CIs) were the summary measures of ORR, FAEs, treatment discontinuation related to AEs, and any severe (grade 3 or 4) AE. We calculated the RRs and CIs, comparing the incidence of each $\mathrm{AE}$ in patients assigned to VEGFR-TKIs with those assigned to placebo alone in the same trial. For one study that reported zero events in the treatment or control arm, we applied the classic half-integer correction to calculate the RR and variance. ${ }^{15}$ The summary 
measures of PFS and OS were HR and the corresponding 95\% CIs, which were extracted from each randomized controlled trial (RCT). For each meta-analysis, the Cochran Q statistic and $I^{2}$ score were first calculated to determine heterogeneity among the proportions of the included trials. ${ }^{16,17}$ For $P<0.10$ values of the Cochran Q statistic, the assumption of homogeneity was deemed invalid and a random-effects model was reported. ${ }^{18}$ Otherwise, results from the fixedeffects model were reported. Finally, potential publication biases were evaluated for severe AEs using Begg's and Egger's tests. ${ }^{19} \mathrm{~A}$ two-tailed $P$-value of $<0.05$ without adjustment for multiplicity was considered statistically significant. The results of the meta-analysis were reported as classic forest plots. All statistical analyses were performed by using Version 2 of the Comprehensive MetaAnalysis program (Biostat, Englewood, NJ, USA).

\section{Results}

\section{Search results}

A total of 146 studies were identified from the database search, of which 141 reports were retrieved for full-text evaluation. Five trials met the inclusion criteria and were included in this systematic review (Figure 1). ${ }^{20-33}$ Table 1 shows the characteristics of the included studies. Overall, a total of 1,614 patients were included for analysis. According to the inclusion criteria of each trial, patients were required to have an adequate renal, hepatic, and hematologic function. In all trials, randomization was between doublet combination group and single agent group. The quality of each included study was roughly assessed according to Jadad score, and all of these trials were double-blind, placebo-controlled trials and thus had a Jadad score of 5 .

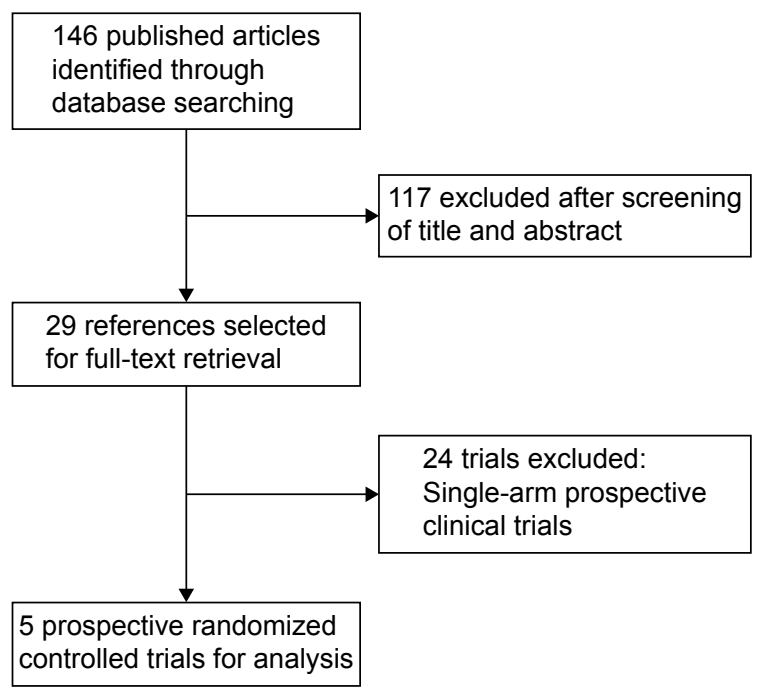

Figure I Studies eligible for inclusion in the meta-analysis.

\section{Safety of VEGFR-TKIs versus placebo}

\section{Fatal adverse events}

FAEs were diagnosed in 43 patients: $31(2.7 \%, 95 \%$ CI: $1.2 \%-6.3 \%)$ in VEGFR-TKI arms and $12(1.7 \%, 95 \% \mathrm{CI}$ : $0.5 \%-5.8 \%)$ in placebo arms. The RR obtained for the studies ranged from 1.01 to 6.55 . Overall, no increased risk was observed for the studies $(\mathrm{RR}=1.24 ; 95 \% \mathrm{CI}$ : 0.65-2.39; $P=0.52$ ) (Figure 2A) using a fixed-effects model $\left(I^{2}=0, P=0.81\right)$.

\section{Any severe AEs}

The incidence of any severe AE related to VEGFR-TKIs and placebo alone was, respectively, 52.2\% (95\% CI: $43.3 \%-60.8 \%$ ) and $46.6 \%$ (95\% CI: $32.9 \%-60.9 \%$ ) by using the random-effects model. The use of VEGFR-TKIs significantly increased the risk of any severe AEs, when compared to placebo (RR=2.63, 95\% CI: 1.72-4.03, $P<0.001$ ) (Figure 2B) using a random-effects model $\left(I^{2}=79.7, P=0.001\right)$.

\section{Treatment discontinuation}

The incidence of treatment discontinuation due to VEGFRTKIs and placebo alone was, respectively, 17.7\% (95\% CI: $13.0 \%-23.8 \%$ ) and $4.6 \%$ (95\% CI: $2.9 \%-7.2 \%$ ) by using the random-effects model. The risk of discontinuing treatment because of AEs was higher with the use of VEGFR-TKIs compared with the controls (RR: 3.80, 95\% CI: 2.56-5.65, $P<0.001$ ) (Figure $2 \mathrm{C}$ ). The test for heterogeneity was nonsignificant and a fixed-effects model was used $\left(I^{2}=25.6, P=0.25\right)$.

\section{Efficacy of VEGFR-TKIs versus placebo}

\section{Overall survival}

The pooled HR for OS did not show significant difference between VEGFR-TKIs and placebo alone (HR: 0.83, 95\% CI: 0.68-1.01, $P=0.06$ ) (Figure 3A). The fixed-effects model was used because there was no significant heterogeneity $\left(P=0.90, R^{2}=0\right)$.

\section{Progression-free survival}

In comparison with placebo alone, VEGFR-TKIs significantly improved PFS (HR: 0.41, 95\% CI: 0.27-0.61, $P<0.001$ ) (Figure 3B). The test for heterogeneity was significant and a random-effects model was used $(P<0.001$, $\left.r^{2}=89.3\right)$.

\section{Objective response rate}

In comparison with placebo, the use of VEGFR-TKIs significantly improved ORR (RR: 8.73, 95\% CI: 1.72-44.4, $P=0.009$ ) (Figure 3C). The test for heterogeneity was 
A

\begin{tabular}{|c|c|c|}
\hline \multirow[t]{2}{*}{ Study name } & \multicolumn{2}{|c|}{ Statistics for each study } \\
\hline & Hazard ratio & Lower limit \\
\hline Leboulleux et al ${ }^{32}$ & 0.830 & 0.519 \\
\hline Wells et $\mathrm{al}^{30}$ & 0.890 & 0.480 \\
\hline Elisei et $\mathrm{al}^{29}$ & 0.980 & 0.631 \\
\hline Brose et $\mathrm{al}^{31}$ & 0.800 & 0.539 \\
\hline Schlumberger et $\mathrm{al}^{33}$ & 0.730 & 0.499 \\
\hline Pooled results & 0.827 & 0.679 \\
\hline
\end{tabular}

Upper limit
1.327
1.650
1.522
1.188
1.068
1.008

Z-value
-0.778
-0.370
-0.090
-1.107
-1.621
-1.881

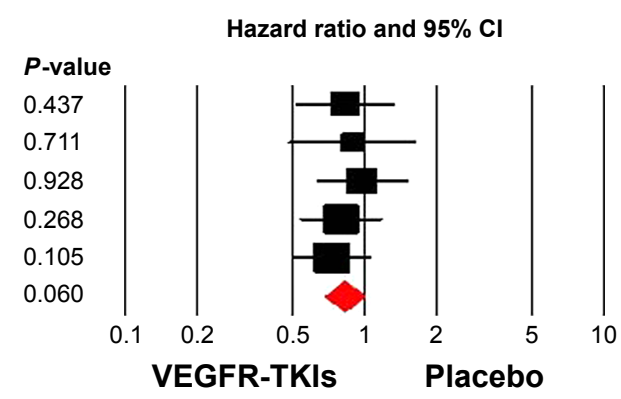

B

\begin{tabular}{|c|c|c|c|}
\hline \multirow[t]{2}{*}{ Study name } & \multicolumn{3}{|c|}{ Statistics for each study } \\
\hline & Hazard ratio & Lower limit & Upper limit \\
\hline Leboulleux et $\mathrm{al}^{32}$ & 0.630 & 0.538 & 0.737 \\
\hline Wells et $\mathrm{al}^{30}$ & 0.460 & 0.308 & 0.686 \\
\hline Elisei et $\mathrm{al}^{29}$ & 0.280 & 0.193 & 0.406 \\
\hline Brose et $\mathrm{al}^{31}$ & 0.590 & 0.454 & 0.767 \\
\hline Schlumberger et $\mathrm{al}^{33}$ & 0.210 & 0.141 & 0.312 \\
\hline Pooled results & 0.408 & 0.273 & 0.608 \\
\hline
\end{tabular}

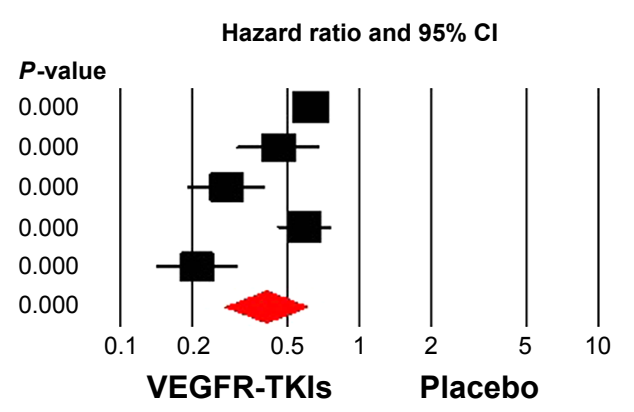

C Study name

\begin{tabular}{|c|c|c|c|c|}
\hline \multicolumn{5}{|c|}{ Statistics for each study } \\
\hline $\begin{array}{l}\text { Risk } \\
\text { ratio }\end{array}$ & $\begin{array}{l}\text { Lower } \\
\text { limit }\end{array}$ & $\begin{array}{l}\text { Upper } \\
\text { limit }\end{array}$ & Z-value & $P$-value \\
\hline 1.521 & 0.448 & 5.165 & 0.672 & 0.501 \\
\hline 1.499 & 0.847 & 2.652 & 1.389 & 0.165 \\
\hline 62.930 & 3.929 & $1,007.854$ & 2.927 & 0.003 \\
\hline 24.612 & 3.362 & 180.174 & 3.154 & 0.002 \\
\hline 42.412 & 10.689 & 168.279 & 5.329 & 0.000 \\
\hline 8.725 & 1.715 & 44.402 & 2.609 & 0.009 \\
\hline
\end{tabular}

Events/total Group-A Group-B

Leboulleux et $\mathrm{al}^{32}$
Wells et $\mathrm{al}^{30}$
Elisei et $\mathrm{al}^{29}$
Brose et $\mathrm{al}^{31}$
Schlumberger et $\mathrm{al}^{33}$
Pooled results

$\begin{array}{ll}6 / 72 & 4 / 73 \\ 45 / 231 & 13 / 100 \\ 61 / 214 & 0 / 109 \\ 24 / 196 & 1 / 201 \\ 169 / 261 & 2 / 131 \\ 305 / 974 & 27 / 614\end{array}$

Risk ratio and $95 \% \mathrm{CI}$

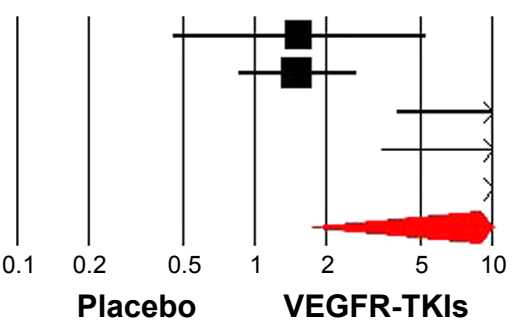

Figure 3 Efficacy associated with VEGFR-TKIs treatment compared with placebo treatment: (A) OS, (B) PFS, (C) ORR.

Abbreviations: $\mathrm{Cl}$, confidence interval; ORR, objective response rate; OS, overall survival; PFS, progression-free survival; VEGFR-TKIs, vascular endothelial growth factor receptor tyrosine kinase inhibitors.

significant and a random-effects model was used $\left(I^{2}=86.6\right.$, $P<0.001)$.

\section{Publication bias}

No publication bias was detected with Begg's or Egger's test for the efficacy and AEs studied, except for any severe AEs (Begg's test, $P=0.05$; Egger's test, $P=0.04$ ) (Table 2).

\section{Discussion}

Increased vascularity has been reported in thyroid cancer. Angiogenesis, especially VEGF signal pathway, plays a pivotal role in tumor growth, progression, and metastasis. ${ }^{34,35}$ Previous research had demonstrated that thyroid cancer cell lines were characterized by high expression of both VEGF and its receptors. ${ }^{36}$ Thus, the VEGF signal pathway has been targeted as a therapeutic option for thyroid cancer. In fact, four VEGFR-TKIs including vandetanib, sorafenib, lenvatinib, and cabozantinib have been approved by the US Food and Drug Administration for use in radioiodine-refractory differentiated thyroid cancer or medullary thyroid cancer; ${ }^{37-39}$ thus, it is anticipated that the use of VEGFR-TKIs would be increasing

Table 2 Publication bias by Begg's and Egger's tests ( $P$-value)

\begin{tabular}{lll}
\hline & Begg's test & Egger's test \\
\hline Overall survival & 0.14 & 0.37 \\
Progression-free survival & 0.14 & 0.08 \\
Objective response rate & 0.22 & 0.10 \\
Fatal adverse event & 0.08 & 0.23 \\
Treatment discontinue & 0.62 & 0.27 \\
Any severe adverse events & 0.05 & 0.04 \\
\hline
\end{tabular}


in the near future. In contrast with traditional chemotherapy agents, VEGFR-TKIs present an anti-VEGF toxicity profile, such as hypertension, ${ }^{40-42}$ proteinuria, ${ }^{43}$ thrombosis, ${ }^{44,45}$ and hemorrhage. ${ }^{46}$ However, the toxicities associated with VEGFR-TKIs in advanced thyroid cancer remains unknown. Moreover, the overall efficacy of VEGFR-TKIs in these patients has not been comprehensively assessed.

Our study, which included 1,614 patients from five RCTs, demonstrates that the use of VEGFR-TKIs in advanced thyroid cancer significantly improves ORR and PFS, and there is also a tendency to improve OS in comparison with the placebo groups. Safety of systematic treatments is of particular importance in palliative setting in advanced thyroid cancer patients, given the potential negative impact on benefit ratio and quality of life. As for toxicities, a previous meta-analysis conducted by Hong et $\mathrm{al}^{47}$ reported that the use of VEGFRTKIs significantly increased the risk of FAEs when compared with controls (odds ratio: $1.85,95 \% \mathrm{CI}: 1.33-2.58, P<0.01$ ), while subgroup analysis according to tumor types showed that the use of VEGFR-TKIs did not significantly increase the risk of FAEs (odds ratio: 2.25, 95\% CI: 0.61-8.30, $P=0.22$ ). Findings of our study indicate that the use of VEGFR-TKIs significantly increased the risk of treatment discontinuation and any severe AEs, but not of FAEs, which is consistent with the findings of a previous study. Based on our results, we conclude that VEGFR-TKIs could be recommended for use in advanced thyroid cancer due to their potential survival benefits, although the use of these drugs would increase the risk of developing treatment discontinuation and any severe AEs, but not of FAEs. Long-term follow-up studies for OS of advanced thyroid cancer patients receiving these VEGFRTKIs are still needed because survival data in these published studies are immature at the time of analysis.

Our study has several limitations. First, this meta-analysis only considers published literature, and lack of individual patient data prevents us from adjusting the treatment effect according to disease and patient variables. Second, toxicity data in RCTs have been reported to be suboptimal and variable as toxicity is usually not the primary outcome measure. Furthermore, there is some degree of subjectivity in the process by which investigators in trials adjudicate whether a patient's death was the result of an AE, cancer progression, or other unrelated causes. Third, these studies exclude patients with poor renal, hematological, and hepatic functions, and are performed mostly at major academic centers and research institutions; the analysis of these studies may not apply to patients with organ dysfunctions and in the community. Finally, as in all meta-analyses, our results may be biased as a result of potential publication bias. However, a funnel plot evaluation for AEs and efficacy does not indicate publication bias except for any severe AEs.

\section{Conclusion}

In conclusion, the use of small-molecule VEGFR-TKIs in advanced thyroid cancer does significantly increase the risk of developing treatment discontinuation and any severe AEs, but not of FAEs, compared with placebo alone. Additionally, the use of VEGFR-TKIs in advanced thyroid cancer significantly improves ORR and PFS, and has a tendency to improve OS. These observations may aid medical oncologists in weighing up the risks and benefits associated with VEGFRTKIs in treating patients with advanced thyroid cancer.

\section{Acknowledgment}

No funding has been received for this study.

\section{Disclosure}

The authors report no conflicts of interest in this work.

\section{References}

1. Pellegriti G, Frasca F, Regalbuto C, Squatrito S, Vigneri R. Worldwide increasing incidence of thyroid cancer: update on epidemiology and risk factors. J Cancer Epidemiol. 2013;2013:965212.

2. Tuttle RM, Haddad RI, Ball DW, et al. Thyroid carcinoma, version 2. 2014. J Natl Compr Canc Netw. 2014;12(12):1671-1680; quiz 1680.

3. Stjepanovic N, Capdevila J. Multikinase inhibitors in the treatment of thyroid cancer: specific role of lenvatinib. Biologics. 2014;8:129-139.

4. Eustatia-Rutten CF, Corssmit EP, Biermasz NR, Pereira AM, Romijn JA, Smit JW. Survival and death causes in differentiated thyroid carcinoma. J Clin Endocrinol Metab. 2006;91(1):313-319.

5. Sherman SI. Cytotoxic chemotherapy for differentiated thyroid carcinoma. Clin Oncol (R Coll Radiol). 2010;22(6):464-468.

6. Minucci S, Pelicci PG. Histone deacetylase inhibitors and the promise of epigenetic (and more) treatments for cancer. Nat Rev Cancer. 2006;6(1):38-51.

7. Fallahi P, Mazzi V, Vita R, et al. New therapies for dedifferentiated papillary thyroid cancer. Int J Mol Sci. 2015;16(3):6153-6182.

8. Ferrari SM, Fallahi P, Politti U, et al. Molecular targeted therapies of aggressive thyroid cancer. Front Endocrinol. 2015;6:176.

9. Fallahi P, Ferrari SM, Santini F, et al. Sorafenib and thyroid cancer. BioDrugs. 2013;27(6):615-628.

10. Carlomagno F, Vitagliano D, Guida T, et al. ZD6474, an orally available inhibitor of KDR tyrosine kinase activity, efficiently blocks oncogenic RET kinases. Cancer Res. 2002;62(24):7284-7290.

11. Rini BI. Sunitinib. Expert Opin Pharmacother. 2007;8(14):2359-2369.

12. Matsui J, Yamamoto Y, Funahashi Y, et al. E7080, a novel inhibitor that targets multiple kinases, has potent antitumor activities against stem cell factor producing human small cell lung cancer H146, based on angiogenesis inhibition. Int J Cancer. 2008;122(3):664-671.

13. Moher D, Cook DJ, Eastwood S, Olkin I, Rennie D, Stroup DF. Improving the quality of reports of meta-analyses of randomised controlled trials: the QUOROM statement. Quality of reporting of meta-analyses. Lancet. 1999;354(9193):1896-1900.

14. Jadad AR, Moore RA, Carroll D, et al. Assessing the quality of reports of randomized clinical trials: is blinding necessary? Control Clin Trials. 1996;17(1):1-12. 
15. Seng S, Liu Z, Chiu SK, et al. Risk of venous thromboembolism in patients with cancer treated with cisplatin: a systematic review and meta-analysis. J Clin Oncol. 2012;30(35):4416-4426.

16. Higgins JP, Thompson SG, Deeks JJ, Altman DG. Measuring inconsistency in meta-analyses. BMJ. 2003;327(7414):557-560.

17. Zintzaras E, Ioannidis JP. Heterogeneity testing in meta-analysis of genome searches. Genet Epidemiol. 2005;28(2):123-137.

18. DerSimonian R, Laird N. Meta-analysis in clinical trials revisited. Contemp Clin Trials. 2015;45:139-145.

19. Egger M, Davey Smith G, Schneider M, Minder C. Bias in meta-analysis detected by a simple, graphical test. BMJ. 1997;315(7109):629-634.

20. Zinner RG, Obasaju CK, Spigel DR, et al. PRONOUNCE: randomized, open-label, phase III study of first-line pemetrexed + carboplatin followed by maintenance pemetrexed versus paclitaxel + carboplatin + bevacizumab followed by maintenance bevacizumab in patients ith advanced nonsquamous non-small-cell lung cancer. J Thorac Oncol. 2015;10(1):134-142.

21. Zhou C, Wu YL, Chen G, et al. BEYOND: a randomized, double-blind, placebo-controlled, multicenter, phase III study of first-line carboplatin/ paclitaxel plus bevacizumab or placebo in Chinese patients with advanced or recurrent nonsquamous non-small-cell lung cancer. J Clin Oncol. 2015;33(19):2197-2204.

22. Galetta D, Cinieri S, Pisconti S, et al. Cisplatin/pemetrexed followed by maintenance pemetrexed versus carboplatin/paclitaxel/bevacizumab followed by maintenance bevacizumab in advanced nonsquamous lung cancer: The GOIM (Gruppo Oncologico Italia Meridionale) ERACLE phase III randomized trial. Clin Lung Cancer. 2015;16(4): $262-273$.

23. Seto T, Kato T, Nishio M, et al. Erlotinib alone or with bevacizumab as first-line therapy in patients with advanced non-squamous nonsmall-cell lung cancer harbouring EGFR mutations (JO25567): an open-label, randomised, multicentre, phase 2 study. Lancet Oncol. 2014; 15(11):1236-1244

24. Niho S, Kunitoh H, Nokihara H, et al. Randomized phase II study of first-line carboplatin-paclitaxel with or without bevacizumab in Japanese patients with advanced non-squamous non-small-cell lung cancer. Lung Cancer. 2012;76(3):362-367.

25. Herbst RS, Ansari R, Bustin F, et al. Efficacy of bevacizumab plus erlotinib versus erlotinib alone in advanced non-small-cell lung cancer after failure of standard first-line chemotherapy (BeTa): a double-blind, placebo-controlled, phase 3 trial. Lancet. 2011;377(9780):1846-1854

26. Reck M, von Pawel J, Zatloukal P, et al. Phase III trial of cisplatin plus gemcitabine with either placebo or bevacizumab as first-line therapy for nonsquamous non-small-cell lung cancer: AVAil. J Clin Oncol. 2009; 27(8):1227-1234.

27. Sandler A, Gray R, Perry MC, et al. Paclitaxel-carboplatin alone or with bevacizumab for non-small-cell lung cancer. N Engl J Med. 2006; 355(24):2542-2550.

28. Johnson DH, Fehrenbacher L, Novotny WF, et al. Randomized phase II trial comparing bevacizumab plus carboplatin and paclitaxel with carboplatin and paclitaxel alone in previously untreated locally advanced or metastatic non-small-cell lung cancer. J Clin Oncol. 2004; 22(11):2184-2191.

29. Elisei R, Schlumberger MJ, Muller SP, et al. Cabozantinib in progressive medullary thyroid cancer. J Clin Oncol. 2013;31(29):3639-3646.
30. Wells SA Jr, Robinson BG, Gagel RF, et al. Vandetanib in patients with locally advanced or metastatic medullary thyroid cancer: a randomized, double-blind phase III trial. J Clin Oncol. 2012;30(2):134-141.

31. Brose MS, Nutting CM, Jarzab B, et al. Sorafenib in radioactive iodine-refractory, locally advanced or metastatic differentiated thyroid cancer: a randomised, double-blind, phase 3 trial. Lancet. 2014; 384(9940):319-328.

32. Leboulleux S, Bastholt L, Krause T, et al. Vandetanib in locally advanced or metastatic differentiated thyroid cancer: a randomised, double-blind, phase 2 trial. Lancet Oncol. 2012;13(9):897-905.

33. Schlumberger M, Tahara M, Wirth LJ, et al. Lenvatinib versus placebo in radioiodine-refractory thyroid cancer. $N$ Engl J Med. 2015; 372(7):621-630.

34. Folkman J. Tumor angiogenesis: therapeutic implications. $N$ Engl J Med. 1971;285(21):1182-1186.

35. Folkman J. Anti-angiogenesis: new concept for therapy of solid tumors. Ann Surg. 1972;175(3):409-416.

36. Lin JD, Chao TC. Vascular endothelial growth factor in thyroid cancers. Cancer Biother Radiopharm. 2005;20(6):648-661.

37. Weitzman SP, Cabanillas ME. The treatment landscape in thyroid cancer: a focus on cabozantinib. Cancer Manag Res. 2015;7:265-278.

38. Yeung KT, Cohen EE. Lenvatinib in advanced, radioactive iodinerefractory, differentiated thyroid carcinoma. Clin Cancer Res. 2015; 21(24):5420-5426.

39. Ferrari SM, Politti U, Spisni R, et al. Sorafenib in the treatment of thyroid cancer. Expert Rev Anticancer Ther. 2015;15(8):863-874.

40. Qi WX, Shen Z, Lin F, et al. Incidence and risk of hypertension with vandetanib in cancer patients: a systematic review and meta-analysis of clinical trials. Br J Clin Pharmacol. 2013;75(4):919-930.

41. Qi WX, Lin F, Sun YJ, et al. Incidence and risk of hypertension with pazopanib in patients with cancer: a meta-analysis. Cancer Chemother Pharmacol. 2013;71(2):431-439.

42. Wu S, Chen JJ, Kudelka A, Lu J, Zhu X. Incidence and risk of hypertension with sorafenib in patients with cancer: a systematic review and meta-analysis. Lancet Oncol. 2008;9(2):117-123.

43. Zhang ZF, Wang T, Liu LH, Guo HQ. Risks of proteinuria associated with vascular endothelial growth factor receptor tyrosine kinase inhibitors in cancer patients: a systematic review and meta-analysis. PLoS One. 2014;9(3):e90135.

44. Sonpavde G, Je Y, Schutz F, et al. Venous thromboembolic events with vascular endothelial growth factor receptor tyrosine kinase inhibitors: a systematic review and meta-analysis of randomized clinical trials. Crit Rev Oncol Hematol. 2013;87(1):80-89.

45. Qi WX, Min DL, Shen Z, et al. Risk of venous thromboembolic events associated with VEGFR-TKIs: A systematic review and meta-analysis. Int J Cancer. 2013;132(12):2967-2974.

46. Qi WX, Tang LN, Sun YJ, et al. Incidence and risk of hemorrhagic events with vascular endothelial growth factor receptor tyrosine-kinase inhibitors: an up-to-date meta-analysis of 27 randomized controlled trials. Ann Oncol. 2013;24(12):2943-2952.

47. Hong S, Fang W, Liang W, et al. Risk of treatment-related deaths with vascular endothelial growth factor receptor tyrosine kinase inhibitors: a meta-analysis of 41 randomized controlled trials. Onco Targets Ther. 2014;7:1851-1867.
OncoTargets and Therapy

\section{Publish your work in this journal}

OncoTargets and Therapy is an international, peer-reviewed, open access journal focusing on the pathological basis of all cancers, potential targets for therapy and treatment protocols employed to improve the management of cancer patients. The journal also focuses on the impact of management programs and new therapeutic agents and protocols on

\section{Dovepress}

patient perspectives such as quality of life, adherence and satisfaction. The manuscript management system is completely online and includes a very quick and fair peer-review system, which is all easy to use. Visit http://www.dovepress.com/testimonials.php to read real quotes from published authors. 